\title{
How to run a sports camp - legally speaking
}

\author{
Steven Monk ${ }^{1}$ \\ Joe Deutsch ${ }^{2}$
}

\begin{abstract}
Camps are a great way to keep kids active throughout the summer and to make money for the program sponsoring them. Planning is needed for a sports camp to be safe for both the camp personnel and the athletes, and to minimize legal negligence. Having a risk management plan in place is important to insure that everyone is aware of the risks of participating. Background checks on camp personnel help ensure the camp leaders and coaches do not have a criminal background. It is important to inspect the facilities/equipment to make sure they are safe to use. Athletic trainers help with injuries that may occur with participation. Supervisors make sure that everyone is accounted for and camp rules help the campers behave in an appropriate manner. When planning activities, it is important to look at the skill level of the athletes. If all of these areas are covered, camps should be legally protected if an issue were to arise.
\end{abstract}

Keywords: Coaching; Sports Camps; Physical Education; Liability.

\section{Introduction}

Running a sports camp can positively impact the development of young athletes if planned and executed properly. A lot of planning is necessary to effectively organize a sports camp, communicate with both participants and parents, and ensure safety for everyone working and participating in the camp (Bjorling \& Deutsch, 2010). If legally important steps are not taken and proper communication with participants fails, the people in charge of the camp can be sued for negligence. Negligence occurs when duty, breach, cause, and harm occur from an incidence (Carpenter, 2000). This article will explain important legal precautions that are needed to protect coaches from negligence. When running camps, it is important to have camp rules, guidelines covering appropriate activities, and supervision at all times. A good risk management plan should also include the following; background checks to ensure instructors are suitable, properly working facilities/equipment, and athletic trainers to respond to injuries that might occur. By following these guidelines, coaches and camp supervisors will mitigate the risks of negligence and ensure the sports camp has the positive impact on youth athletes as planned.

\section{Risk Management Plan}

In order to run a legally sound sports camp, it is important to make the campers and parents aware of the possible injuries and risks while attending the camp. Proper communication is the first step to ensure camp leaders are not held liable because parents and athletes were not aware of the risks at the camp. A Risk Management Plan for coaches to follow includes: Insurance,

\footnotetext{
${ }^{1}$ M.S., North Dakota State University, Graduate Assistant, HNES, steven.monk@ndsu.edu

2 Ph.D., North Dakota State University, Associate Professor, HNES, joe.deutsch@ndsu.edu
} 
Monk, S., \& Deutsch, J. (2016). How to run a sports camp - legally speaking. International Journal of Human Sciences, 13(1), 2068-2071. doi:10.14687/ijhs.v13i1.3598

Release Forms, Waivers, Indemnification, and Assumptions of Risk. The following paragraphs will describe these forms in more detail and identify why they are necessary.

When planning a camp, insurance is a must since it helps protect the organization and people running the camp. According to Carpenter (2000), "Professional Liability Insurance is available for multiple organizations surrounding athletics and would protect the camp from claims made for negligence against the camp" (pg. 77). This insurance helps protect the insured from expenses in a lawsuit. Employer's Liability Insurance helps protect individuals such as coaches and other staff for claims of negligence made on an individual person. Employers Liability Insurance does not cover everyone like professional liability insurance. Professional Liability Insurance can cost a lot of money depending how many staff are being used throughout the camp, which is why Employers Liability Insurance might be better option for smaller camps.

A "release" is an agreement made after an injury has occurred. This is usually a contract that relieves potential liability and includes a sum of money to the person of injured party, who in return, gives a promise not to sue (Carpenter, 2000). It is not recommended that camps do this since people can void the contract and still sue. It is best to take care of problems using waivers, which is explained in the next paragraph.

A "wavier" is a written agreement before injuries occur, that makes people aware of possible risk of injury (LeMar \& Deutsch, 2015). Waivers are not legally binding when it comes to minors. It is important to have all waivers signed by responsible adults when hosting a camp (Carpenter, 2000). Any camp brochure or flyer should include a waiver when signing up for a camp. This waiver inclusion will minimize a possible legal problem in advance.

Indemnification is when one person promises to pay the bills for someone else. Just like waivers and releases, this is a written agreement that needs to be signed by the coaches or camp leaders. If facilities are being rented from an outside group, an indemnification agreement can be made, which states that the camp group will cover costs associated with injuries that may result from the use of the facility, should someone sue (Carpenter, 2000). An example of this is if a clinician for a camp wants to use a high school for facilities, the school would more than likely make the clinician sign an indemnification agreement saying that he/she is responsible if any injuries might occur within the high school.

Coaches should also have a form that includes "Assumptions of Risk". This form has two parts that include understanding the nature of the risks by the participant, and voluntary consent by the participant (Carpenter, 2000). It is important for campers to understand all risks, so that if they get hurt, they should know that it comes with the nature of the sport. If a camper gets hurt and did not understand this coming into the camp, it can cause legal trouble for the coaches. The athlete and parents should sign this form so they both understand the risks.

The American Camp Association (ACA) is an organization that helps ensure the quality of camps by providing professionals with necessary waivers to legally protect everyone (Walsh, 2011). This organization has a website http://www.acacamps.org, which coaches might find helpful to ensure that they have a quality camp. After a risk management plan has been organized, it is important to have athletic trainers to properly address any injuries that may occur.

\section{Athletic Trainers}

Every camp should have an athletic trainer on staff because of the probability of someone getting injured. Most coaches are first aid/CPR certified, but trainers have more knowledge about injuries and treatment techniques. Athletic trainers will have the necessary first aid equipment to take care of minor injuries like cuts and bloody noses. Trainers and coaches should also have health examinations or physicals for the athletes explaining their medical history and if medical conditions were recently identified (Spengler, Connaughton, \& Pittman, 2006). This informs both the trainers and camp staff to monitor certain campers in case something were to occur. Once the athletic trainers have been gathered, it is important to have background checks on all personnel working the camp. 
Monk, S., \& Deutsch, J. (2016). How to run a sports camp - legally speaking. International Journal of Human Sciences, 13(1), 2068-2071. doi:10.14687/ijhs.v13i1.3598

Background Checks
Camps usually involve staff other than coaches, which are labeled as counselors. Counselors not only help with instruction of the camp, but also for supervising the campers, since they need to be accounted for at all times (LeMar \& Deutsch, 2015). Having background checks on the counselors and coaches is recommended when working with children. Most parents would not feel comfortable having their children be taught by someone with certain criminal backgrounds. Some states require background checks among coaches and camp personnel, while others do not. It is important to keep in mind that background checks take time and can be expensive depending on how many people are getting screened. The ACA offers background checks for counselors and other camp personnel. The cost can be anywhere from 10 dollars to 60 dollars depending if the test is local or national (Spengler, Connaughton, \& Pittman, 2006). Once background checks are in place, the facilities/equipment must be checked over.

\section{Facilities/Equipment}

Before a camp begins, it is important to check the facilities for safety, to ensure the space available is adequate, and validate that all of the equipment is working and safe. First, if the facilities are not safe, it either needs to be fixed promptly, or not used at all. Camp directors owe the duty of providing safe facilities no matter what the situation is (Carpenter, 2000). Second, facilities should be looked at to see how many campers could safely use them. Having too many people attempting to use a single piece of equipment can result in injury. Having separate sessions can be an effective approach to handling the situation of an unsafe number of participants. If separate sessions are not possible, have a set number on how many campers can attend the camp. Third, all equipment must be working properly. As mentioned before, if equipment is not working properly, it either needs to be replaced or removed. Coaches are liable for any facilities and equipment that are not safe. Once the facilities/equipment have been checked over, it is important to plan how the camp will be supervised.

\section{Supervision}

Supervisors are responsible for watching over the campers throughout the day. Supervisors can be coaches, counselors, or other camp personnel that make sure everyone is acting in an appropriate manner. If something happens and no one saw what happened, the camp supervisors can be held liable. It is important to plan supervision before the camp starts so that everyone working is on the same page. Obviously the campers will be coached during sessions, but they need to be supervised outside of sessions as well. Supervisors must walk the campers to and from the dorms to the facilities. This ensures that all campers get safely to where they need to be. Supervisors must also stay in the dorms throughout the night, in case any issues were to arise. If a supervisor has to leave their post, it is important to make sure someone is covering for them. Lastly, supervisors must know what to do when an emergency occurs. If an emergency does occur, it is important it have an Emergency Action Plan (EAP), which is planned out by coaches, athletic trainers, supervisors, and local EMS. An EAP would have a list of numbers to call if an emergency were to call. For example, if a pipe were to burst in the building, maintenance should be called and if a camper were to fall down the stairs slicing their head open, '911' should be called. This plan will also tell camp staff what to do during natural disasters such as earthquakes and tornados. Other areas covered in an EAP include fire escape, bomb threats, and chemical spills. Supervisors should be aware of first aid kits and AED's and know how to use them if necessary. '911' should be dialed if the situation is serious (Spengler, Connaughton, \& Pittman, 2006). After camp leaders have covered supervision, camp rules must be created so the campers act in an appropriate manner. 


\section{Camp Rules}

Camp Rules let the campers know what behaviors are acceptable and not acceptable. It is important to have rules because they not only make sure everyone stays on task, but also can reduce liability. Camp Rules should be communicated to all campers both verbally and in written form, letting them know what is expected. Consequences for not following the rules need to be included as well to let the campers know that action will be taken. Each rule will have different consequences if not followed, so it is important to cover them all. Once the camp rules have been arranged, the final step is to plan out appropriate activities for the campers.

\section{Appropriate Activities}

Before a camp starts, it is important for coaches to plan out the activities for camp. One big consideration to take into account is the skill level of the campers. Most camps will have athletes of differing abilities, which means activities have to be fairly basic since the less experienced campers will not be able to perform the advanced techniques. If the skill set is not there, athletes will become discouraged, unmotivated and off task, potentially resulting in injury (Prichard \& Deutsch, 2015). Some camps can be designed for advanced athletes; in that case more advanced skills can be shown. Coaches can be liable if they are making campers participate in advanced skills and activities that they do not have the prerequisite skill for.

\section{Conclusion}

Camps are a great way to keep kids active throughout the summer and to make money for the program sponsoring them (Christianson, Breker, \& Deutsch, 2012). Planning is needed for a sports camp to be safe for both the camp personnel and the athletes, and to minimize legal negligence. Having a risk management plan in place is important to insure that everyone is aware of the risks of participating. Background checks on camp personnel help ensure the camp leaders and coaches do not have a criminal background. It is important to inspect the facilities/equipment to make sure they are safe to use. Athletic trainers help with injuries that may occur with participation. Supervisors make sure that everyone is accounted for and camp rules help the campers behave in an appropriate manner. When planning activities, it is important to look at the skill level of the athletes. If all of these areas are covered, camps should be legally protected if an issue were to arise.

\section{References}

Bjorling, S. \& Deutsch, J. (2010). How to run a baseball hitting camp in a small town market, Journal of Youth Sports, 6(1), 3-9.

Carpenter, L. (2000). Legal concepts in sport: A primer (4th ed.). Urbana, Ill., Illinois: Sagamore.

Christianson, N., Breker, M., \& Deutsch, J. (2012). How to run a soccer camp for adolescents (age 6-14), Journal of Youth Sports, 7(1), 13-18.

LeMar, B. \& Deutsch, J. (2015). How to run a successful and educational basketball camp, International Journal of Human Sciences, 12(1), 1182-1188.

Prichard, A. Deutsch, J. (2015). The effects of motivational climate on youth sport participants, Physical Educator, 72(special issue), 200-2014.

Spengler, J., Connaughton, D., \& Pittman, A. (2006). Risk Management in Sport and Recreation. Champaign, IL, Illinois: Human Kinetics.

Walsh, D. (2011). Strategies for developing a university-sponsored youth sports summer camp, Journal of Physical Education, Recreation \& Dance, 82(9), 24-27. 